\title{
Evaluating the effectiveness of a hybrid sorbent resin in removing fluoride from water
}

\author{
${ }^{1}$ M. Rahmani Boldaji; ${ }^{2 *}$ A. H. Mahvi; ${ }^{1,3}$ S. Dobaradaran; ${ }^{1}$ S. S. Hosseini \\ ${ }^{1}$ School of Public Health, Tehran University of Medical Science, Tehran, Iran \\ ${ }^{2}$ School of Public Health and Center for Environmental Research, Tehran University of Medical Science, \\ Tehran, Iran \\ ${ }^{3}$ Bushehr University of Medical Science, Bushehr, Iran \\ Received 25 June 2009; $\quad$ revised 22 July 2009; accepted 15 August 2009; $\quad$ available online 1 September 2009
}

\begin{abstract}
In some regions of the world, the concentration of fluoride in groundwater is high. To reduce the amount of fluoride to acceptable drinking water standard, it is highly recommended to treat the water. Fluoride adsorption in aqueous solution by a hybrid resin was studied in this research because of its functional groups likeness with goethite. Kinetic data showed that $\mathrm{F}$ adsorption was rapid in the beginning and maximum uptake occurred in within $10 \mathrm{~min}$ and equilibrium reached within $100 \mathrm{~min}$. The experimental results showed that fluoride adsorption was influenced by $\mathrm{pH}$ of solution and optimum operating $\mathrm{pH}$ was in the range of 3 to 5.5. Langmuir model was applicable to the present study and $\mathrm{F}$ ions were exchanged with hydroxide ions in nano-scaled structure on the surface of sorbent. This adsorbent with $61 \%$ efficiency is suitable for the regions where F concentration is less than $4 \mathrm{mg} / \mathrm{L}$.
\end{abstract}

Keywords: Fluoride removal; Functional groups; Goethite; Hybrid resin; Langmuir model

\section{INTRODUCTION}

Fluoride is an essential mineral that in permissible guideline level (WHO, 2006) is beneficial to mankind in dental protection and excessive intake led to various disorders and diseases such as crippling skeletal fluorosis, brittle bones, cancer (lung and bladder), infertility in women, brain and hepatit damage and Alzheimer syndrome (Chinoy, 1991; Shivarajashankara et al., 2001; Guo et al., 2003; Jamode et al., 2004; Mahvi et al., 2006a; Dobaradaran et al., 2008a).

Wide varieties of minerals, including fluorspar, rock phosphate, cryolite, apatite, mica and thermal waters especially with high $\mathrm{pH}$ have significant level of F. Aluminum smelters that use the F salt cryolite, brick and iron work, coal fired power stations which discharge wastewater with high $\mathrm{F}$ concentrations are contributing to entry $\mathrm{F}$ to the environment (De la Puente et al., 1997; Abe et al., 2004; Dobaradaran et al., 2009a) .Groundwater as drinking water is usually the main source of F intake (Dobaradaran et al., 2009b), groundwater with high $\mathrm{F}$ concentrations occurs in India, Pakistan, West Africa, Thailand, China, Sri Lanka,

\*Corresponding Author Email: ahmahvi@yahoo.com Tel.: +98912 321 1827; Fax: +9821 88950188
Southern Africa, Iraq, Iran, Sudan, Ethiopia, Uganda, Kenya and the United Republic of Tanzania (WHO, 2006; Abdel-Ghani et al., 2007; Kumar et al., 2009) and because of daily fluoride intake importance, there are many studies about fluoride contents in water and black tea (Mahvi et al., 2006b; Nouri et al., 2006; Dobaradaran et al., 2008b). Precipitation, ion exchange (Hichour et al., 1999), membrane separation (Ndiaye et al., 2005) and adsorption (Abe et al., 2004) are examples of several technologies that have been developed for F removal. Among various techniques, adsorption is a promising technology, in which $\mathrm{F}$ is concentrated onto a small adsorbent mass. Sorption media, including bone charcoal, activated alumina and clay are packed in columns and used for a period of time; this material after saturating are renewed or regenerated.

Several researches have been studied and confirmed with a large number of natural materials (Magnesite, natrolite, clinoptilolite, goethite, kaolinite, bentonite, zeolite(s), serpentine, alkaline soil, kaolinitic clay, China clay) for F removal (Bower and Hatcher, 1967; Rao and Viraraghavan, 2002; Fan et al., 2003). Iron and aluminum oxides such as GFH (Kumar et al., 2009), goethite 
(Jinadasa et al., 1993), activated alumina (Hiemstra and Van Riemsdijk, 1999; Ku and Chiou, 2002) and alumina cement granules (Tang et al. 2009) play an important role in removal of anions from aqueous solutions.

In the present study, the adsorption potential of innovative hybrid sorbent (Lewatit FO 36) consisting of a combination of a polymeric anion exchange resin and an iron oxide with a goethite $(\alpha-\mathrm{FeOOH})$ structure has been assessed for $F$ removal from water. This research was performed in Tehran University of medical science from September until December 2008.

\section{MATERIALS AND METHODS}

\section{Materials}

Lewatit FO 36 was purchased from the producer (LANXESS Company, Germany). It is a macroporous, monodispersed, polystyrene-based resin which is doped with a nano-scaled film of iron oxide covering the inner surface of the pores of the polymer bead. Appearance of the adsorbent is brown and mean bead size of the material is $0.35 \mathrm{~mm}$. This adsorbent stability is at $\mathrm{pH}$ range of 4-14. A stock F solution was prepared by dissolving $221 \mathrm{mg}$ of $\mathrm{NaF}$ (Merck) in $1.0 \mathrm{~L}$ of distilled water. The $\mathrm{pH}$ of distilled water was in the range of 6.8 to 7.3 . The batch method by stirring (390 rpm) was used to study the adsorption of F on Lewatit FO 36 and the effects of contact time and $\mathrm{pH}$ were investigated. Standard acid and base solutions $(0.1 \mathrm{~N}$ $\mathrm{H}_{2} \mathrm{SO}_{4}$ and $\mathrm{NaOH}$ solutions) were used for $\mathrm{pH}$

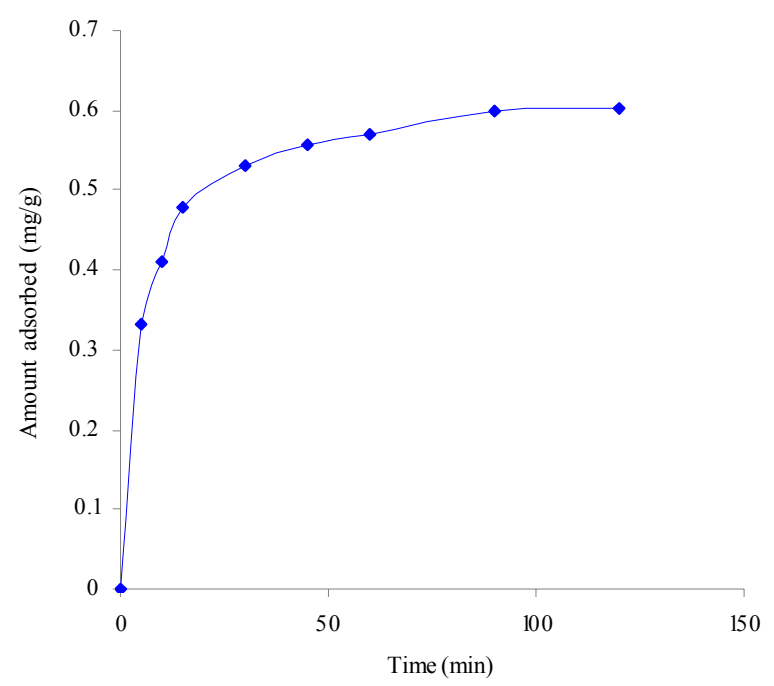

Fig. 1: Effect of contact time on fluoride adsorption on Lewatit FO $36(\mathrm{~F}$ initial concentration $=6 \mathrm{mg} / \mathrm{L}$, Lewatit FO 36 dose $=3 \mathrm{~g} / \mathrm{L}, \mathrm{pH}=5 / 5$, Temp. $=25^{\circ} \mathrm{C}$ ) adjustment. The $\mathrm{pH}$ of solution was measured using pH meter (metrohm E520). Batch experiment with 1000 $\mathrm{mL}$ volume were carried out at room temperature $(25 \pm$ $2{ }^{\circ} \mathrm{C}$ ) by stirring a fixed mass of dry resin and $6 \mathrm{mg} / \mathrm{L} \mathrm{F}$ solution until equilibrium was reached. After agitation for a specified period of time, solid phase was separated with sedimentation and the concentration of $F$ was determined by UV-vis spectrophotometer (Hatch-Long DR-5000). All experiments were performed in duplicates and the average values were reported. The amount of $\mathrm{F}$ adsorbed at time $\mathrm{t}$, q-t, was determined from the mass balance equation:

$\mathrm{q}_{\mathrm{t}}=\left(\mathrm{C}_{0}-\mathrm{C}_{\mathrm{t}}\right) \mathrm{V} / \mathrm{m}$

\section{RESULTS AND DISCUSSION \\ Effect of $p H$}

$\mathrm{pH}$ is one of the important factors that influences most of adsorption processes. $F$ adsorption was investigated for $6 \mathrm{mg} / \mathrm{L} \mathrm{F}$ concentration in the $\mathrm{pH}$ range of 3 to 9 as shown in Fig. 2. The highest adsorption of $61 \%$ was observed at $\mathrm{pH}=5.5$. F adsorption was clearly affected by $\mathrm{pH}$ of the solution and decreased with increasing pH (Jinadasa et al., 1993; Ayoob et al., 2008; Kumar et al., 2009)

Surface hydroxyl groups in the structure of functional groups are amphoteric and can act as either an acid or base by adsorbing or desorbing $\mathrm{H}^{+}$. In high $\mathrm{pH}$ presence of $\mathrm{OH}^{-}$ions can interference with $\mathrm{F}$

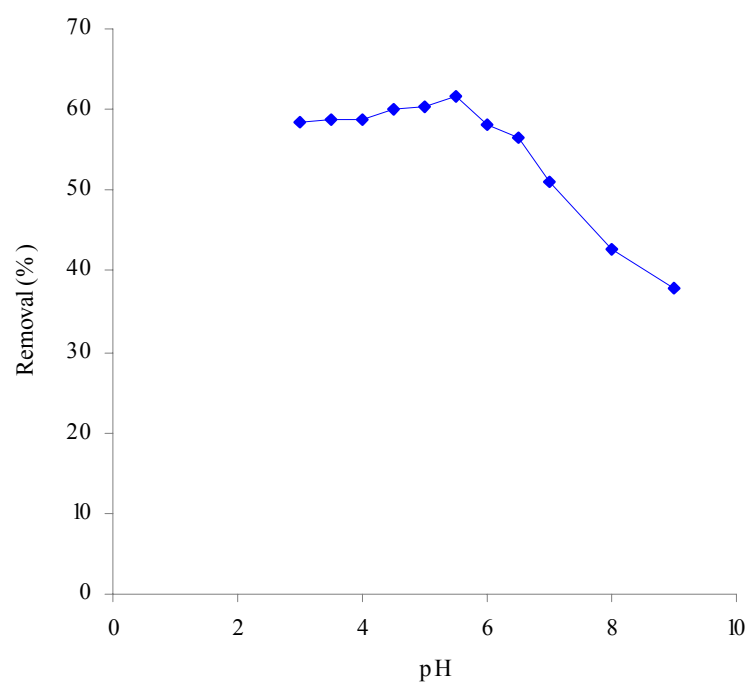

Fig. 2: Effect of $\mathrm{pH}$ on fluoride adsorption on Lewatit FO 36 ( F initial concentration $=6 \mathrm{mg} / \mathrm{L}$, Lewatit $\mathrm{FO} 36$ dose $=5 \mathrm{~g} / \mathrm{L}$, temp $=25{ }^{\circ} \mathrm{C}$, contact time $\left.=120 \mathrm{~min}\right)$ 
adsorption because of the same charge and radius of $\mathrm{F}$ and hydroxide ions and the competition for the active site by $\mathrm{OH}^{-}$and electrostatic repulsion of $\mathrm{F}$ ions by the negatively charged adsorbent surface at high $\mathrm{pH}$ (Ayoob et al., 2008; Kumar et al., 2009). (Any FeOOH dissolution did not appear at pH 3).

\section{Effect of contact time}

$F$ adsorption as a function of contact time was studied for determining the equilibration time. Effect of contact time on amount of $\mathrm{F}$ adsorbed with Lewatit FO 36 is shown in Fig. 1. Maximum uptake was obtained within the first $10 \mathrm{~min}$ of contact time that increased rapidly and after that rose slowly in the following 100 min. A further increase in contact time had a negligible effect on the adsorption. In some studies a similar trend was also observed during the adsorption of $\mathrm{F}$ onto other metal oxy-hydroxide materials (Tang et al., 2009).

\section{Equilibrium of adsorption}

Fruindlich and Langmuir isotherms are useful models for the description of adsorption process by different adsorbents. Equilibrium adsorption of $\mathrm{F}$ was conducted at seven different concentrations, ranging from 3 to 6 $\mathrm{mg} / \mathrm{L}$ at $\mathrm{pH}=5.5$. The Freundlich model (Freundlich, 1906) refers to surface heterogeneity of the adsorbent:

$\log \left(\mathrm{q}_{\mathrm{e}}\right)=\log \mathrm{K}_{\mathrm{f}}+1 / \mathrm{n} \log \mathrm{C}_{\mathrm{e}}$

Where, $\mathrm{K}_{\mathrm{f}}$ and $1 / \mathrm{n}$ are Freundlich constants, associated with adsorption capacity and adsorption intensity, respectively.

The Freundlich plots between $\log \mathrm{q}_{\mathrm{e}}$ and $\log \mathrm{C}_{\mathrm{e}}$ are shown in Fig 3.

Langmuir model assumes uniform energies of adsorption onto the surface and no transmigration of the adsorbate in the plane of the surface.

$1 / q_{e}=1 / q_{m}+1 / q_{m} b C_{e}$

Where, qe is amount adsorbed at equilibrium concentration $\mathrm{C}_{\mathrm{e}}, \mathrm{q}_{\mathrm{m}}$ and $\mathrm{b}$ are the Langmuir constants representing adsorption capacity and Langmuir constant energy of adsorption, respectively. The plots of $1 / q e$ as a function of $1 / C_{e}$ for the adsorption of $F$ are shown in Fig. 3. The monolayer capacity $\left(\mathrm{q}_{\mathrm{m}}\right)$ has been evaluated from intercept of this plots and Langmuir constant (b) has been evaluated from the slope of graph. The plots were found liner with $>0.98$ correlation coefficients that showed that Langmuir model was applicable to the present study. This means that the F

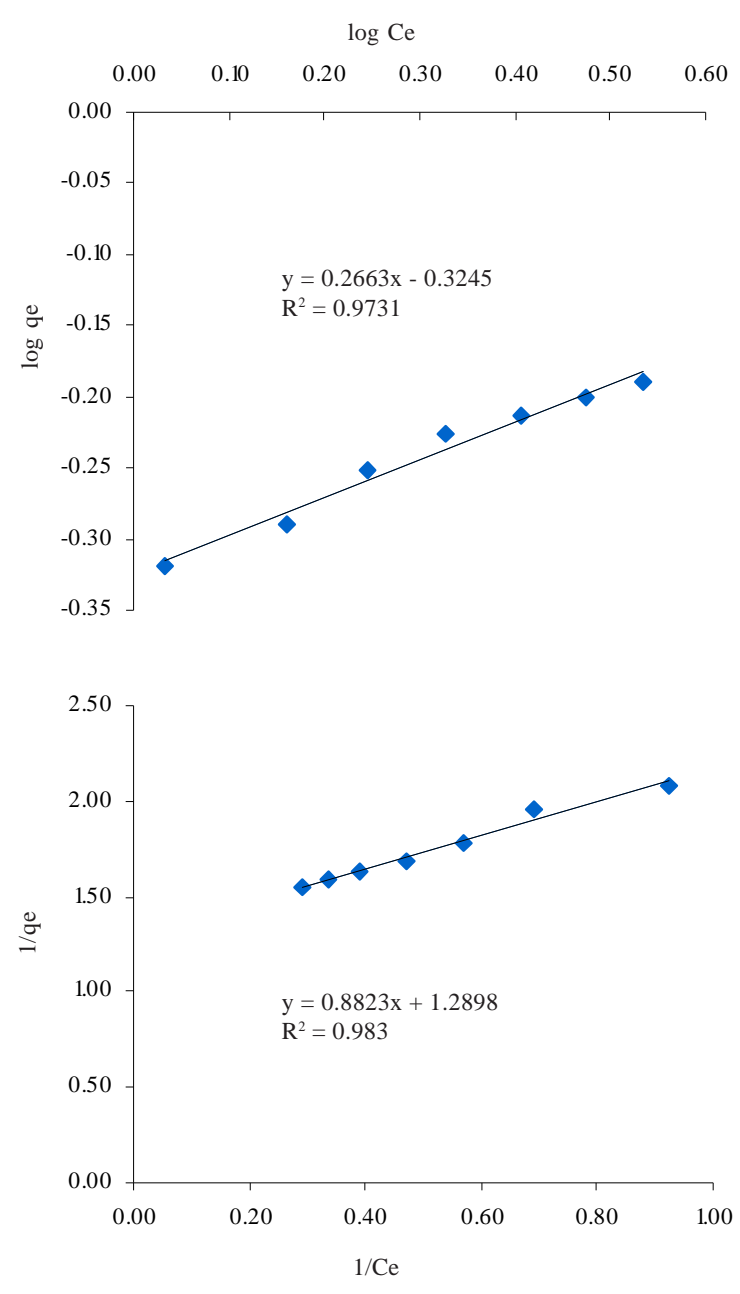

Fig. 3: Isotherms modeling of $\mathrm{F}$ adsorption on Lewatit FO36.1)Fruindlich Isotherm 2)Langmuir model

adsorption is in the form of monolayer coverage on the surface of the adsorbent (Jinadasa et al., 1993). In this study, it has been demonstrated that Lewatit FO 36 can remove fluoride with $61 \%$ efficiency where $\mathrm{F}$ concentration is less than $4 \mathrm{mg} / \mathrm{L}$. The optimum removal was observed at 3 to $5.5 \mathrm{pH}$ ranges and Langmuir model was applicable for this study.

\section{REFERENCES}

Abdel-Ghani, N. T.; Hefny, M.; El-Chagbaby G. A. F., (2007). Removal of lead from aqueous solution using low cost abundantly available adsorbents. Int. J. Environ. Sci. Tech., 4 (1), 67-73 (7 pages).

Abe, I.; Iwasaki, S.; Tokimoto, T.; Kawasaki, N.; Nakamura, T.; Tanada, S., (2004). Adsorption of fluoride ions onto carbonaceous materials. J. Colloid Interf. Sci., 275 (1), 3539 (5 pages). 
Ayoob, S.; Gupta, A. K.; Bhakat, P. B.; Bhat, V. T., ( 2008). Investigations on the kinetics and mechanisms of sorptive removal of fluoride from water using alumina cement granules. Chem. Eng. J., 140 (1-3), 6-14 (9 pages).

Bower, C. A.; Hatcher, J. T., (1967). Adsorption of fluoride by soils and minerals. Soil Sci., 103 ( 3 ), 151-154 (4 pages).

Chinoy, N. J., (1991). Effects of fluoride on physiology of some animals and human beings. Indian J. Environ. Toxicol., 1 (1), 17-32 (16 pages).

De la Puente, G.; Pis, J. J.; Menendez, J. A; Grange, P., (1997). Thermal stability of oxygenated functions in activated carbons. J. Anal. Appl. Pyrol., 43 (2), 125-138 (14 pages).

Dobaradaran, S.; Fazelinia, F.; Mahvi, A. H.; Hosseini, S. S., (2009a). Particulate airborne fluoride from an aluminium production plant in Arak, Iran. Fluoride, 42 (3), 208-212 (5 pages).

Dobaradaran, S.; Mahvi, A. H.; Dehdashti, S., (2008b). Fluoride content of bottled drinking water available in Iran. Fluoride, 41 (1), 93-94 (2 pages).

Dobaradaran, S.; Mahvi, A. H.; Dehdashti, S.; Abadi, D. R. V.; Tehran, I., (2008a). Drinking water fluoride and child dental caries in Dashtestan, Iran. Fluoride, 41 (3), 220-226 (7 pages).

Dobaradaran, S.; Mahvi, A. H.; Dehdashti, S., Dobaradaran, S.; Shoara, R., (2009b). Correlation of fluoride with some inorganic constituents in groundwater of Dashtestan, Iran. Fluoride, 42 (1), 50-53 (4 pages).

Fan, X.; Parker, D. J.; Smith, M. D., (2003). Adsorption kinetics of fluoride on low cost materials. Water Res., 37 (20), 49294937 (9 pages).

Freundlich, H. M. F., (1906). Over the adsorption in solution. J. Phys. Chem., 57, 370-485 (16 pages).

Guo, X.; Sun, G.; Sun, Y., (2003). Oxidative stress from fluorideinduced hepatotoxicity in rats. Fluoride, 36 (1), 25-29 (5 pages).

Hichour, M.; Persin, F.; Molenat, J.; Sandeaux, J.; Gavach, C., (1999). Fluoride removal from diluted solutions by Donnan dialysis with anion-exchange membranes. Desalination, 122 (1), 53-62 (10 pages).

Hiemstra, T.; Van Riemsdijk, W. H., (1999). Fluoride adsorption on goethite in relation to different types of surface sites. J. Colloid Interf. Sci., 225 (1), 94-104 (11 pages).

Jamode, A. V.; Sapkal, V. S.; Jamode, V. S., (2004). Defluoridation of water using inexpensive adsorbents. J. Indian Ins. Sci., 84 (5), 163-171 (9 pages).
Jinadasa, K. B. P. N.; Dissanayake, C. B.; Weerasooriya, S. V. R.; Senaratne, A., (1993). Adsorption of fluoride on goethite surfaces-implications on dental epidemiology. Environ. Geol., 21 (4), 251-255 (5 pages).

$\mathrm{Ku}$, Y.; Chiou, H. M., (2002). The adsorption of fluoride ion from aqueous solution by activated alumina. Water Air Soil Poll., 133 (1-4), 349-361 (13 pages).

Kumar, E.; Bhatnagar, A.; Ji, M.; Jung, W.; Lee, S. H.; Kim, S. J.; Lee, G.; Song, H.; Choi, J. Y.; Yang, J. S.; Jeon, B. H., (2009). Defluoridation from aqueous solutions by granular ferric hydroxide (GFH). Water Res., 43 (2), 490-498 (9 pages).

Mahvi, A. H.; Zazoli, M. A.; Younecian, M.; Esfandiari, Y., (2006b). Fluoride content of Iranian black tea and tea liquor. Fluoride, 39 (4) 266-268 (3 pages).

Mahvi, A. H.; Zazoli, M. A.; Younecian, M.; Nicpour, B.; Babapour, A., (2006a). Survey of fluoride concentration in drinking water sources and prevalence of DMFT in the 12 years old students in Behshar City. J. Med. Sci., 6 (4), 658661 (4 pages).

Ndiaye, P. I.; Moulin, P.; Dominguez, L.; Millet, J. C.; Charbit, F., (2005). Removal of fluoride from electronic industrial effluent by RO membrane separation. Desalination, 173 (1), 25-32 (8 pages).

Nouri, J.; Mahvi, A. H.; Babaei, A.; Ahmadpour, E., (2006). Regional pattern distribution of groundwater fluoride in the Shush aquifer of Khuzestan County, Iran. Fluoride, 39 (4), $321-325$ (5 pages).

Rao, J. R.; Viraraghavan, T., (2002). Biosorption of phenol from an aqueous solution by Aspergillus niger biomass. Bioresource Tech., 85 (2), 165-171 (7 pages).

Shivarajashankara, Y. M.; Shivashankara, A. R.; Bhat, P. G.; Rao, S. H., (2001). Effect of fluoride intoxication on lipid peroxidation and antioxidant systems in rats. Fluoride, 34 (2), 108-113 (6 pages).

Tang, Y.; Guan, X.; Su, T.; Gao, N.; Wang, J., (2009). Fluoride adsorption onto activated alumina: Modeling the effects of $\mathrm{pH}$ and some competing ions. Colloid. Surface. A, 337 (13), 33-38 (6 pages).

WHO, (2006). Guidelines for Drinking-water Quality: Incorporating First Addendum, Recommendations, In: World Health Organization, $3^{\text {rd. Ed., Vol. 1, Geneva. }}$

AUTHOR (S) BIOSKETCHES
Rahmani Boldaji, M., M.Sc. student, School of Public Health, Tehran University of Medical Science, Tehran, Iran.
Email: rahmany1980@gmail.com
Mahvi, A. H., Assisstant professor, School of Public Health and Center for Environmental Research, Tehran University of Medical Science,
Tehran, Iran. Email: ahmahvi@yahoo.com
Dobaradaran, S., Ph.D. candidate, School of Public Health, Tehran University of Medical Science, Tehran, and Bushehr University of
Medical Science, Bushehr, Iran. Email: sina_dobaradaran@yahoo.com
Hosseini, S. S., B.Sc., School of Public Health, Tehran University of Medical Science, Tehran, Iran. Email: ssa_hosseiny@yahoo.com

How to cite this article: (Harvard style)

Rahmani Boldaji, M.; Mahvi, A. H.; Dobaradaran, S.; Hosseini, S. S., (2009). Evaluating the effectiveness of a hybrid sorbent resin in removing fluoride from water. Int. J. Environ. Sci. Tech., 6 (4), 629-632 